\title{
Descriptions of Zygometapodus gen. nov. and a new species of Stenometapodus (Hemiptera: Heteroptera: Coreidae)
}

\author{
Harry BRAILOVSKY \\ Departamento de Zoología, Instituto de Biología, UNAM, Apdo Postal 70153, Ciudad de México, México; e-mail: coreidae@ib.unam.mx
}

Accepted:

$12^{\text {th }}$ April 2018

Published online: $29^{\text {th }}$ May 2018

\begin{abstract}
The genus Stenometapodus Breddin, 1903 (Coreidae: Coreinae: Acanthocephalini) is redescribed and one new species, Stenometapodus aurantiacus sp. nov., is described from Brazil. The new species is distinguished by a combination of color patterns and morphological characters, such as the shape of pronotum. A key to the known species of Stenometapodus is included. A new genus, Zygometapodus gen. nov., is proposed for Stenometapodus castaneus Blöte, 1938. New distribution records for Zygometapodus castaneus (Blöte, 1938) comb. nov. from Bolivia and Peru are provided. Dorsal photos of each species of Stenometapodus and Zygometapodus are also provided.
\end{abstract}

Key words. Heteroptera, Coreidae, Stenometapodus, Zygometapodus, new combination, new genus, new species, key, Brazil, Neotropical Region

http://zoobank.org/urn:lsid:zoobank.org:pub:0720399E-5358-4D5E-ABB4-CD4FAF8277DC

(C) 2018 The Authors. This work is licensed under the Creative Commons Attribution-NonCommercial-NoDerivs 3.0 Licence.

\section{Introduction}

BREDDIN (1903) described the genus Stenometapodus based on a male collected in Bolivia, which became the type species with the binomial combination $S$. v-luteum Breddin, 1903. In the same paper he described a variety based on a female also collected in Bolivia, which he named S. v-luteum var. impictus Breddin, 1903. Subsequently, BцÖTЕ (1938) added a new species, S. castaneus Blöte, 1938, from Peru, raised S. v-luteum var. impictus to species rank with the binomen $S$. impictus, recording distribution of S. v-luteum and S. impictus in Peru. BRAILOVSKY (1984) recognized four species, including one new: S. ambiguus Brailovsky, 1984, S. castaneus, S. impictus, and $S$. v-luteum. Later Brailovsky \& BarreRA (1999), analyzed the genus Salapia Stål, 1860 and transferred Salapia guttifer Stål, 1860 (see STÅL 1860) to the genus Stenometapodus. Upon examination of all the known species in the genus and comparing their morphologies it became obvious that one of them, $S$. castaneus differed significantly from the rest; therefore, a new genus is proposed and described for it here, indicating the characters that define it. In addition, a new species of Stenometapodus is described from Brazil.

\section{Material and methods}

Pictures were taken with a Nikon D200 camera. The following abbreviations are used for the institutions cited here:

AMNH American Museum of Natural History, New York, USA;

CASC California Academy of Sciences, San Francisco, California, USA;

FSCA Florida State Collection of Arthropods, Gainesville, Florida, USA;

MABR Museo Argentino de Ciencias Naturales "Bernardino Rivadavia", Buenos Aires, Argentina;

NHMW Naturhistorisches Museum Wien, Austria;

RMNH Naturalis Biodiversity Centre, Leiden, the Netherlands;

SMFD Forschungsinstitut und Naturmuseum Senckenberg, Frankfurt am Main, Germany;

UNAM Colección Entomológica, Instituto de Biología, Universidad Nacional Autónoma de México, Mexico;

USNM National Museum of Natural History, Smithsonian Institution, Washington, D.C., USA. 


\section{Taxonomy}

\section{Stenometapodus Breddin, 1903}

Stenometapodus Breddin, 1903: 373 (original description). Stenometapodus: PAckauskas (2010): 29 (catalogue).

Redescription. Body size medium to large, over $20 \mathrm{~mm}$. Head wider across eyes than long, quadrate, not declivent, and dorsally flat; tylus projecting beyond juga as strongly compressed plate, with apex extending forward as a single subacute rectangular projection; juga apically globose, not visible from above, deflexed below antenniferous tubercle; antenniferous tubercle protruding, unarmed; posttylar sulcus simple, deep; antennae shorter than total body length; antennal segment I stouter than segments II to IV, slightly curved outward, longer than maximal length of head and internally ridged; antennal segments II to III cylindrical, IV fusiform; antennal segment IV the longest, III the shortest, and I longer than II; antennal segment IV shorter than II and III together; antennal segment I flattened inwards; ocelli slightly raised, close to eye; preocellar pit small, deep; eyes hemispheric, protuberant; postocular tubercle moderately exposed; buccula short, nearly semicircular, elevated, not projecting beyond antenniferous tubercle, not spinose; rostrum short, reaching posterior border of mesosternum or anterior border of metasternum.

Thorax. Pronotum wider than long, trapezoid, declivent, narrowed anteriorly and diverging posteriorly to form a prominent spinose humerus; collar clearly demarcated; frontal angles obtuse; anterolateral margins obliquely straight, finely nodulose; humeral angles remarkably spinose, each spine-like projection apically acute, directed backward; posterolateral margins entirely serrate to nodulose; posterior margin straight; triangular process elongate or short, and acute; callar region flat, not clearly differentiated or slightly raised, impunctate; anterior lobe of pronotal disk smooth, posterior lobe densely punctate, striate, with a shallow median longitudinal ridge. Prosternum deeply concave; meso-, and metasternum not sulcate; metapleural supracoxal spine difficult to see in males, absent in females; metathoracic scent gland peritreme with a single auricle. Legs. Male hind trochanter with or without two ventral tubercles near apex; in females always smooth; fore and middle femora slender, ventrally armed with two rows of spines, and dorsally smooth; hind femur strongly incrassate in males, less so in females, slightly surpassing the apex of abdomen, ventrally with two rows of spines, and dorsally with one to three rows of stout to acute spines; in each sex the inner and outer surface of hind femora are longitudinally sulcate, more deeply in males; fore and middle tibiae cylindrical, unarmed, sulcate; hind tibiae longer than abdomen, inner and outer surface slightly expanded; inner expansion strongly spinose and outer expansion smooth in both sexes; outer expansion narrow, armed with short spines or denticles. Scutellum longer than wide, apically subacute; disk flat, triangular, coarsely and transversely striated, and clothed with erect setae. Hemelytra. Macropterous, extending beyond the apex of the last abdominal segment; clavus and corium finely and densely punctate; veins prominent.
Abdomen. Connexivum raised above terga; upper surface of whole body of males densely covered with short to long spines; in females always smooth; abdominal terga without medial furrow; abdominal spiracles closer to anterior border of each sternite. Male genitalia. Genital capsule. Posteroventral edge with lateral angles rounded, and area between them with small sized concavity, extending dorsally into a shallow, medially flattened tongue. Female genitalia. Abdominal sternite VII with fissure scarcely visible; plica quadrate, broad, reaching apical third of sternite VII; gonocoxae I triangular, in caudal view close to each other; paratergite VIII subtriangular with spiracle visible; paratergite IX quadrate, longer than VIII.

Differential diagnosis. The genus Stenometapodus is similar to Meluchopetalops Breddin, 1903, Cervantistellus Brailovsky \& Barrera, 2005, Empedocles Stål, 1867 and Ichilocoris Brailovsky \& Barrera, 2001 by having the hind tibiae expanded, antennal segment I internally ridged, and posterior angles of male connexival segments $\mathrm{V}$ and VI spinose.

In Empedocles the pronotal disk is clearly tuberculate and impunctate; the collar indistinct; and the outer expansion of hind tibiae in both sexes with one or two deep shallow emarginations. In the other genera the pronotal disk lacks tubercles, and is clearly punctate; the collar well demarcated; and the outer expansion of hind tibia in both sexes is lanceolate or narrowed. Stenometapodus is clearly distinguished from all the genera by having the hind tibiae longer than abdomen; the humeral angles of pronotum exposed and acute; the antennal segment IV is shorter than segments II and III combined; and scutellar disk with erect setae.

In Meluchopetalops the hind tibiae are shorter than the abdomen; the humeral angles of pronotum are obtuse; the antennal segment IV is longer than segments II and III combined; and the scutellum lacks erect setae.

In Cervantistellus the upper margin of male connexival segments VI and VII has one robust spine apically truncated and located near the anterior margin, and eventually with a few tubercles along the entire edge; and the humeral angles are produced into broad sharp spines, turning backwards. In comparison, the Stenometapodus has the upper margin of male connexival segments VI to VII remarkably spined and denticulate; and the humeral angles are clearly acute.

Ichilocoris can be defined by having the apex of the scutellum globose, with a creamy yellow callosity. In the other genera, the apex is flat and subacute.

\section{Stenometapodus aurantiacus sp. nov.} (Fig. 1)

Type locality. Brazil, Rio de Janeiro, Itatiaia.

Type material. HоLотуре: ${ }^{+}$, BRAZIL: Itatiaya, 31.i.1927, col. Dr. Seitz (SMFD). Paratype: 1 +, BRAZIL: Itatiaya, 19.i.1927, col. Dr. Seitz (UNAM).

Description. Female (holotype). Dorsal coloration. Head shiny black, with inner face of antenniferous tubercle and longitudinal stripe running between ocelli yellow; antennal segment I dark reddish brown, II-III dark castaneous orange with apical third black, and IV dark castaneous 
orange; pronotum, scutellum (apex yellowish orange), clavus and corium shiny black; claval and corial veins dark reddish brown; hemelytral membrane black; connexival segments pale yellowish orange with anterior and posterior border dark brown; abdominal segments dorsally black.

Ventral coloration. Head black with tylus and the area close to eyes pale yellow; bucculae dark yellow; rostral segments I-III dark reddish brown and IV pale yellowish orange. Pro-, meso-, and metapleura shiny black; metathoracic scent gland peritreme and evaporative area shiny orange; inner border of acetabula yellow; metaacetabula tinged with bluish green reflections; prosternum black; mesosternum black with a yellow longitudinal stripe running across the middle; basal half of metasternum dark orange and distal half black; fore leg with coxae shiny reddish brown with a dark yellow spot near apical third; trochanters and femora shiny reddish brown; basal half of tibiae dark castaneous orange and apical half pale golden yellowish orange, except apical joint reddish brown; basal and middle tarsal segment pale orange, and apical segment pale orange with apical third reddish brown; middle legs with coxae and trochanters shiny reddish brown; femora pale orange with basal and apical border, spines, and outer surface near apical third reddish brown; tibiae pale golden yellowish orange with basal joint reddish brown; tarsi pale orange; hind leg with coxae and trochanters shiny reddish brown; femora dorsally shiny reddish brown, ventrally pale orange and spines reddish brown; tibiae and tarsi pale golden yellowish orange with apex of each spine dark brown. Middle third of abdominal sternites III-VII and pleural margin pale orange with a wide black longitudinal stripe between them; abdominal spiracles black with pale orange rim; posterior border of each sternite dark brown; middle third of abdominal sternite VII black; gonocoxae I black; paratergites VIII and IX black with wide orange discoidal spot at middle third.

Structure. Body size large, over $20.0 \mathrm{~mm}$. Head. Antennal segment I moderately robust, thickest, slightly curved outward and longer than maximum length of head; rostrum reaching posterior border of mesosternum. Thorax. Pronotum: callar region slightly raised; triangular process elongate, stout. Abdomen. Connexivum with dorsal surface armed with short spines.

Measurements (in mm; $\mathrm{n}=1$ ). Total body length 23.10 . Head length 2.29; width across eyes 2.41; interocular distance 0.94 ; interocellar distance 0.37 ; preocular distance 1.30; antennal segments: I - 3.96, II - 3.84, III - 2.97, IV -5.70 . Pronotal length 4.15; maximum width across humeral angles 8.06. Scutellar length 2.79, basal width 2.66.

Male. Unknown.

Differential diagnosis. Stenometapodus aurantiacus is the only species of the genus with the hind tibiae pale golden yellowish-orange. In the other known species hind tibiae are black or reddish brown or dark castaneous. See the key below.

Etymology. The species epithet is the Latin adjective aurantiacus (-a, -um), meaning orange, referring for the golden yellowish-orange color of its hind tibiae.

Distribution. Brazil: Rio de Janeiro.

\section{Key to the known species of Stenometapodus}

1 Clavus yellow. 2

- Clavus black to reddish brown, with or without metallic green reflections.

2 Corium unicolorous; antennal segment I black; dorsal face of hind femora with basal third black (Fig. 2). ..... S. v-luteum Breddin, 1903

- Corium bicolorous; antennal segment I dark castaneous orange with basal third black; dorsal face of hind femora with basal third pale yellowish orange (Fig. 3)................................ S. ambiguus Brailovsky, 1984

3 Hind tibiae pale golden-yellowish orange (Fig. 1). ...... S. aurantiacus sp. nov.

- Hind tibiae black or reddish brown or dark castaneous.

4 Corium pale castaneous orange with black discoidal spots near middle third; pronotal disk pale castaneous orange with pale yellowish orange spots at each side of middle line; acetabula pale yellowish orange; hind femora unicolorous (Fig. 4). ... S. guttifer (Stål, 1859)

- Corium black to pale brown, with veins dark reddish orange; pronotal disk black or pale reddish orange with or without posterior margin black, and lacking pale yellowish orange spots; acetabula black, with or without metallic green reflections; hind femora bicolorous (Figs 5-6). S. impictus Breddin, 1903

\section{Zygometapodus gen. nov.}

Type species. Stenometapodus castaneus Blöte, 1938, here designated.

Description. Body medium sized to large, over $20.00 \mathrm{~mm}$.

Head wider than long across eyes, quadrate, not declivent, and dorsally flat; tylus projecting beyond juga as strongly compressed plate, with apex extending forward as a single subacute rectangular projection; juga apically globose, apices not visible from above, deflexed below antenniferous tubercle; antenniferous tubercle protruding, unarmed; posttylar sulcus simple, deep; antennae shorter than total body length; antennal segment I stouter than segments II to IV, slightly curved outward, longer than maximal length of head, with inner face longitudinally ridged. Antennal segments II and III cylindrical, IV fusiform; antennal segment I longer than II, III the shortest and segment IV the longest, subequal to II and III combined. Ocelli slightly raised, close to eye; preocellar pit small, deep; eyes hemispheric, protuberant; postocular tubercle moderately exposed. Bucculae short, nearly semicircular, elevated, not projecting beyond antenniferous tubercle, not spinose. Rostrum short, reaching posterior border of mesosternum or anterior border of metasternum.

Thorax. Pronotum. Wider than long, trapezoid, declivent, narrowed anteriorly and diverging posteriorly to form a prominent spinose humerus; collar clearly demarcated; frontal angles obtuse; anterolateral margins obliquely straight, finely nodulose; humeral angles remarkably spinose, each spinose projection apically acute, directed backward; anterior half of posterolateral margins serrate, posterior half smooth; posterior margin 
straight; triangular processes absent; callar region flat, not clearly differentiated, scarcely punctate; anterior lobe of pronotal disk smooth, posterior lobe densely punctate, striate, with shallow median longitudinal ridge.
Prosternum deeply concave; meso-, and metasternum not sulcate; metapleural supracoxal spine hard to see in males, absent in females; metathoracic scent gland peritreme with two completely separated auricles. Legs. Male hind
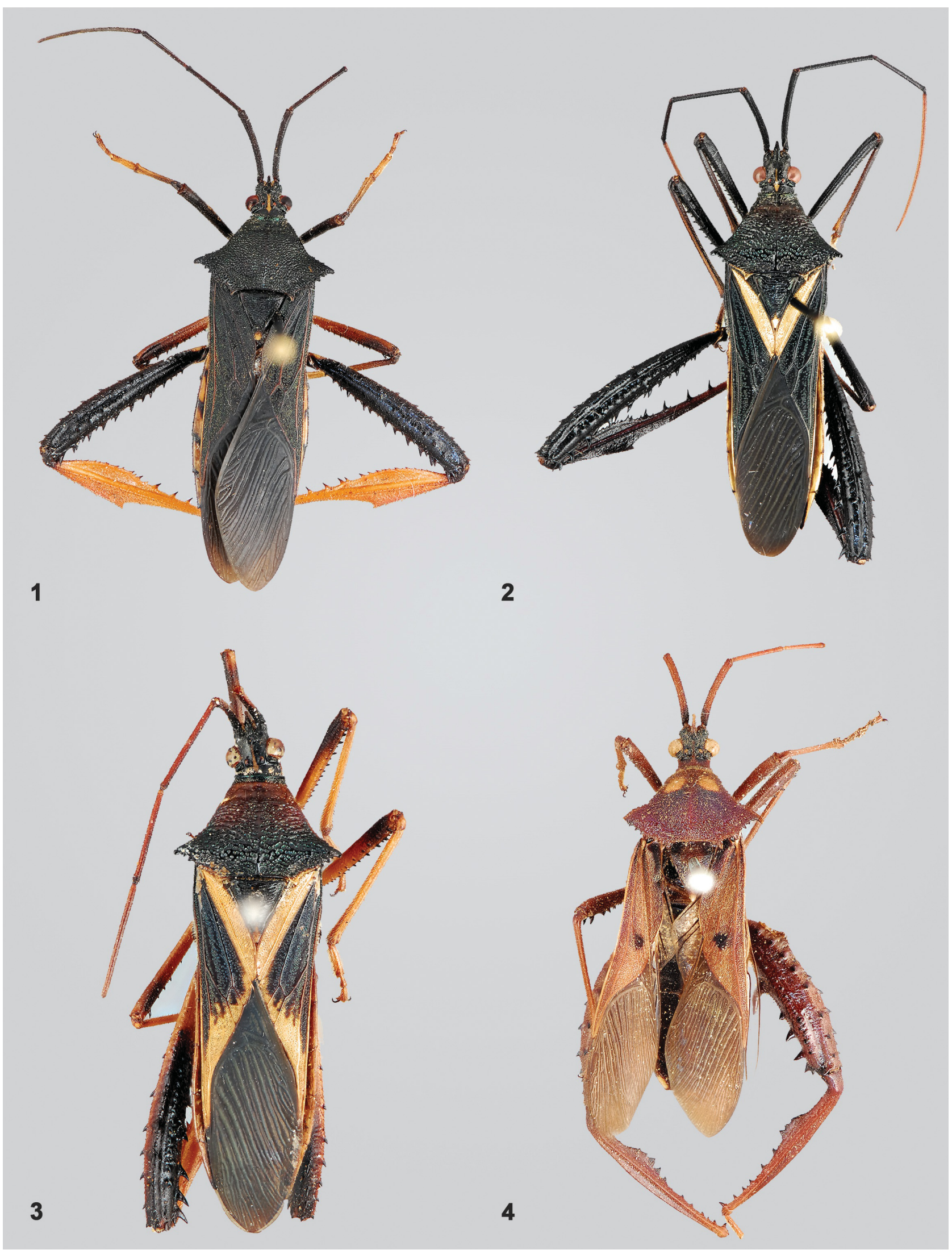

Figs 1-4. Stenometapodus spp., habitus in dorsal view. 1 - S. aurantiacus sp. nov. (female); 2 - S. v-luteum Breddin, 1903 (female); 3 - S. ambiguus Brailovsky, 1984 (female); 4 -S. guttifer (Stål, 1859) (male). 
trochanter with two ventral tubercles near apex, smooth in females; fore and middle femora slender, ventrally armed with two rows of spines, and dorsally smooth; hind femora strongly incrassate in males, slightly in females,

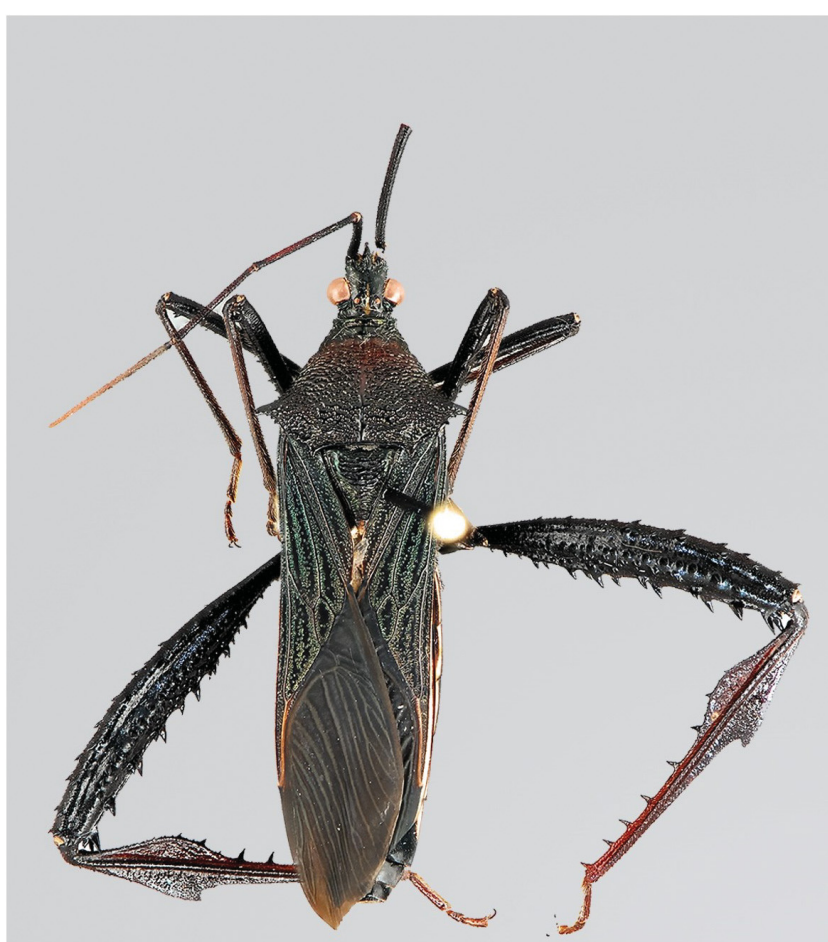

5

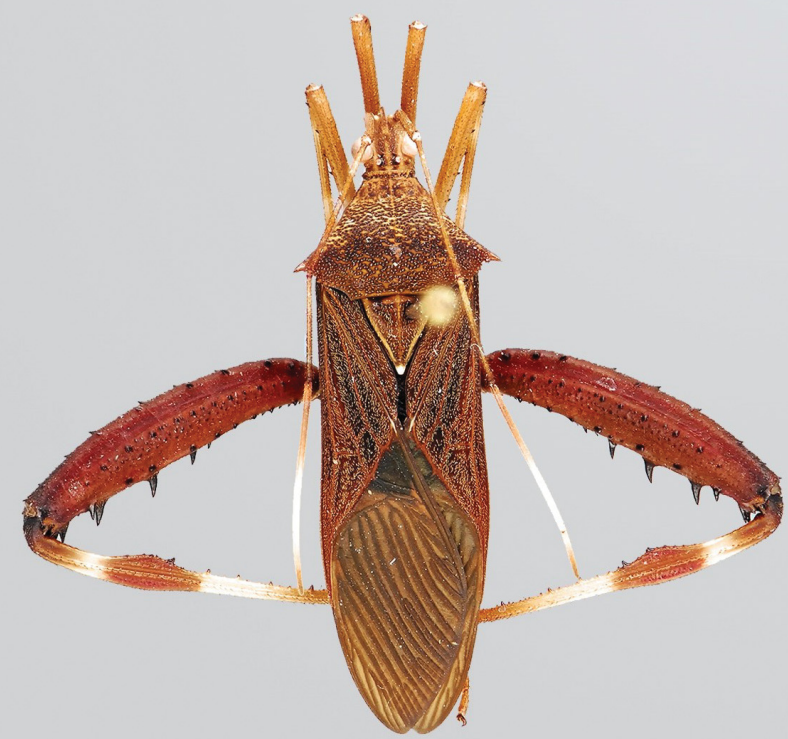

7 conspicuously surpassing the apex of abdomen, ventrally with two rows of spines, and dorsally with one to three rows of stout to acute spines; inner and outer surface of male hind femora longitudinally sulcate, in female gently

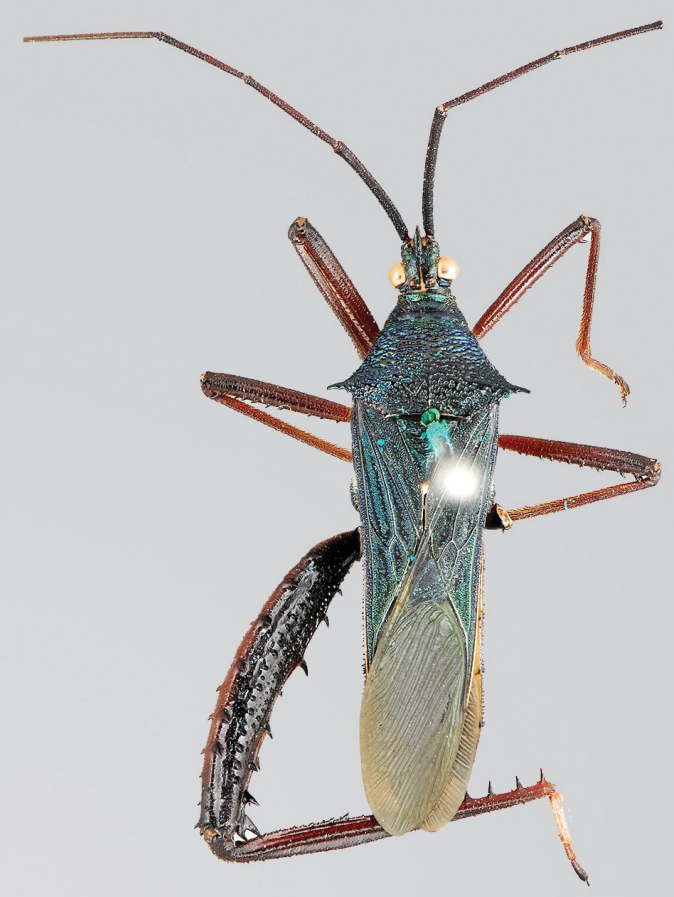

6

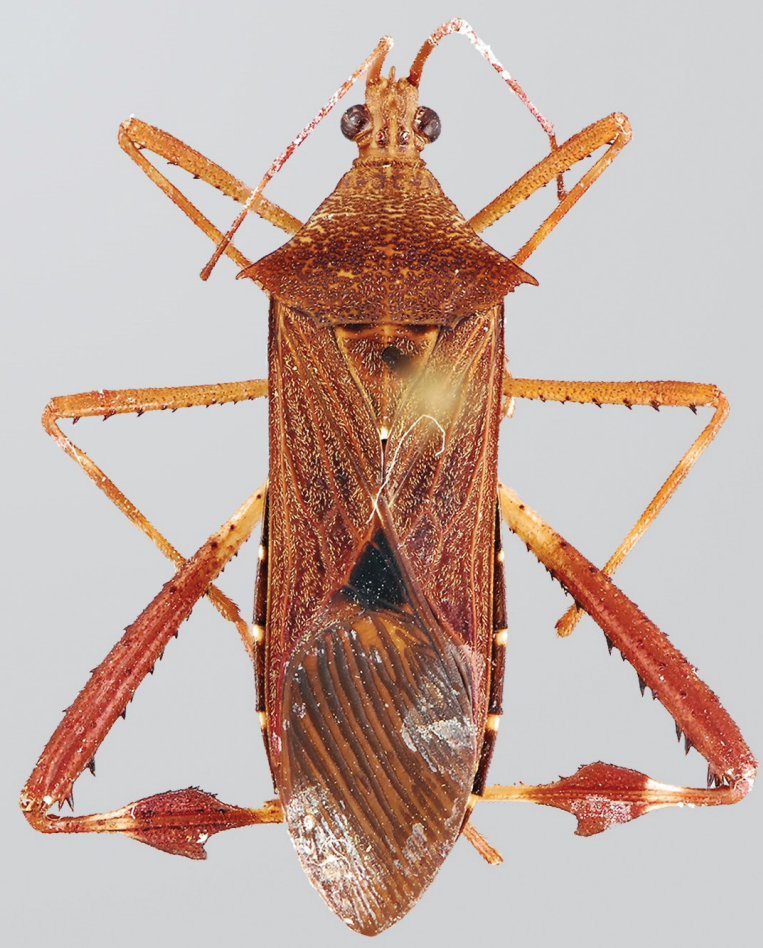

8

Figs 5-8. 5-6 - Stenometapodus impictus Breddin, 1903, dorsal view (5 - female, 6 - male). 7-8-Zygometapodus castaneus (Blöte, 1938), dorsal view $(7$ - male, 8 - female). 
and not easy to see. Fore and middle tibiae cylindrical, sulcate, and unarmed; hind tibiae longer than abdomen, inner and outer surface expanded, widely in females, more narrowly in males; inner expansion spinose in each sex; outer expansion smooth in each sex; inner and outer expansion in each sex extending $23 \%$ of the maximal length of hind tibiae. Scutellum longer than wide, apically subacute; disk flat, triangular, coarsely and transversely striated, and clothed with erect and decumbent setae. Hemelytra macropterous, extending beyond the apex of the last abdominal segment; clavus and corium finely and densely punctate; veins prominent.

Abdomen. Connexivum raised above terga; upper surface smooth in each sex; posterior angle of segment $\mathrm{V}$ and VI with a short acute spine; abdominal terga without medial furrow; abdominal spiracles closer to anterior border of each sternite. Male genitalia. Genital capsule. Posteroventral edge with lateral angles rounded, and area between them provided with a small sized concavity, extending dorsally, into shallow, medially flattened tongue. Female genitalia. Abdominal sternite VII with plica and fissure; plica transversally rectangular, narrow, just reaching anterior margin of sternite VII; gonocoxae I triangular, apically rounded, in caudal view close each other; paratergite VIII subtriangular with spiracle visible; paratergite IX squarish, longer than VIII.

Differential diagnosis. The new genus has affinities with Stenometapodus by having the hind tibiae expanded; connexival segments V and VI with a short acute spine; antennae shorter than total body length; antennal segment IV being the longest; collar present, well demarcated; pronotal disk without tubercles; hind tibiae longer than abdomen; humeral angles spinose, apically acute; and mesosternum and metasternum not sulcate.

In Zygometapodus, the metathoracic scent gland peritreme is bilobed, with two completely separated auricles; the antennal segment IV subequal to segments II and III combined; connexival segments III to VII in males with upper surface smooth; the callar region slightly punctate; the triangular process of pronotum absent; the anterior half of posterolateral margin of pronotum serrate, and posterior half smooth; and in females the abdominal sternite VII has plica and fissure; the plica transversaly rectangular, narrow, and just reaching the anterior margin of sternite VII.

In Stenometapodus, the metathoracic scent gland peritreme has a single auricle; the antennal segment IV shorter than segments II and III combined; connexival segments III to VII in males densely covered with large to short spines; the callar region impunctate; the triangular process of pronotum elongate or short and acute; anterior and posterior margin of the posterolateral margins of pronotum serrate and nodulose; and in females the abdominal sternite VII with plica; fissure scarcely visible; plica quadrate, broad, reaching apical third of sternite VII.

Etymology. The new genus is named for its similar appearance to Stenometapodus. The word is composed of the Greek prefixes zygo- (for union or pair) and meta(posterior), and the noun poús (= foot, leg), latinized. The gender is masculine.
Zygometapodus castaneus (Blöte, 1938) comb. nov. (Figs 7-8)

Stenometapodus castaneus Blöte, 1938: 277 (original description). Stenometapodus castaneus: BrallovsKy (1984): 66 (key to species); PACKAUSKas (2010): 29 (catalogue).

Material examined. BOLIVIA: 1 , La Paz, Guanay, x.-xi.1953, L. E. Peña (USNM); 2 $\delta$, Chapare (Yungas), i.1949, Williner (MABR). PERU: 3 o 1 , Madre de Dios, Rio Tambopata Reserve, 30 air km SW of Puerto Maldonado, 290 m, 6.-10.xi.1979, 1.-26.xi.1982, E. S. Ross (CASC, FSCA, UNAM); 1 , Prov. Paucartambo, Department Cuzco, shores of Rio Cosnipata, Haciendo Maria, 3.iii.1952, F. Woytkowski (AMNH).

Redescription. Male. Dorsal coloration. Head pale castaneous orange with ocellar tubercle, posterolateral tubercle and two narrow longitudinal stripes running between ocelli to the apex of tylus pale brown; antennal segment I yellow, II pale castaneous orange, III pale castaneous orange with apical third dark castaneous orange, and IV yellow with basal joint dark castaneous orange; pronotum pale castaneous orange with punctures dark brown; scutellum pale castaneous orange with lateral margins, anterior margin and median longitudinal stripe dark yellow; apex yellowish white; clavus and corium dark castaneous; claval and corial veins pale castaneous orange; hemelytral membrane pale brown, veins darker; basal angle black and near with or without pale orange irregular spot; connexival segments III to VII black with anterior third yellow; all terga black.

Ventral coloration. Head pale brown, with buccula and longitudinal stripe close to each eye yellow; rostral segments I to IV pale castaneous orange; pro-, meso-, and metasternum pale brown with diffuse pale castaneous orange spot lateral to midline; pro-, meso-, and metapleura pale castaneous orange with punctures dark brown; metathoracic scent gland peritreme pale castaneous orange with anterior and posterior lobes dark brown; fore and middle legs pale castaneous orange, with spines dark brown; hind leg with coxae and trochanters dark castaneous brown; femora ventrally dark reddish brown and dorsally dark castaneous orange; femoral spines dark reddish brown; tibiae dark reddish brown to dark brown, with two yellow to pale orange rings, one near basal third, the second close to middle third; tarsi pale castaneous orange; abdominal sterna pale castaneous orange; rim of each spiracle black; pleural margins III to VII pale yellowish orange with upper pleural margin black except the anterior third yellow; genital capsule pale castaneous orange.

Measurements (in mm; $\mathrm{n}=1$ ). Total body length 20.12 . Head length 1.98; width across eyes 2.10; interocular distance 0.86; interocellar distance 0.32; preocular distance 0.94; antennal segments: I - 4.03, II - 3.72, III - 3.03, IV -6.82 . Pronotal length 3.47 , maximum width across humeral angles 5.95. Scutellar length 2.35, basal width 1.98.

Female. Color and habitus similar to male. Connexival segments VIII and IX pale brown to dark orange; dorsal abdominal segments VIII and IX dark orange with posterior margin pale brown; genital plates castaneous orange.

Measurements (mm). Total body length 20.48. Head length 1.87; width across eyes 2.11; interocular distance 0.82 ; interocellar distance 0.38 ; preocular distance 0.99 ; antennal segments: I - 4.03, II - 3.53, III - 3.10, IV - 6.63. 
Pronotal length 3.65, maximum width across humeral angles 6.22. Scutellar length 2.41, basal width 2.10 .

Distribution. Bolivia (new record), Peru (BlÖTE 1938).

\section{Acknowledgments}

I thank Randall T. Schuh (AMNH), Vincent Lee and Christopher C. Grinter (CASC), Julieta Brambila (FSCA), Diego Carpintero (MABR), Herbert Zettel (NHMW), Ivonne D. van Nierop (RMNH), Wolfgang A. Naessig (SMFD), and Thomas J. Henry (USNM) for loan of the specimens. Special thanks go to Ernesto Barrera (UNAM) for the photographs, to Julio Cesar Montero (UNAM) and Diana Martinez Almaguer (UNAM) for the design of the plates and to Oscar Federico Francke Balle (UNAM) for the comments on the manuscript.

\section{References}

BLÖTE H. G. 1938: Catalogue of the Coreidae in the Rijksmuseum van Natuurlijke Historie. Part IV. Coreinae, Third Part. Zoologische Mededeelingen (Leiden) 20: 275-308.
BRAILOVSKY H. 1984: Una nueva especie del género Stenometapodus Breddin y algunas notas acerca de Empedocles tenuicornis (Westwood) (Hemiptera-Heteroptera-Coreidae-Acanthocephalini). Anales del Instituto de Biología, Universidad Nacional Autónoma de México, Serie Zoología 54 [1983]: 63-68.

BRAILOVSKY H. \& E. BARRERA 1999: An analysis of the genus Salapia Stål with description of six new species, and some taxonomic rearrangements (Hemiptera: Heteroptera: Coreidae: Acanthocephalini). Pan-Pacific Entomologist 75: 130-146.

BREDDIN G. 1903: Beiträge zur Hemipteran fauna der Anden. Sitzungsberichte der Gesellschaft Naturforschender Freunde zu Berlin 8: $366-383$.

PACKAUSKAS R. 2010: Catalog of the Coreidae, or Leaf-Footed Bugs of the New World. Fort Hays Studies, Fourth Series 5: 1-270.

STÅL C. 1860: Till kannedomen om Coreidae. Öfversigt af Kongliga Svenska Vetenskaps-Akademiens Förhandlingar 16 [1859]: 449-475. 
